\title{
Unveiling the mysteries of hereditary prion diseases in Brazil
}

\author{
Desvendando os mistérios das doenças priônicas hereditárias no Brasil
}

Abelardo Q. C. Araújo 1,2

1 Universidade Federal do

Rio de Janeiro, Instituto de

Neurologia Deolindo Couto,

Rio de Janeiro RJ, Brasil;

${ }^{2}$ Fundação Oswaldo Cruz, Instituto

Nacional de Infectologia Evandro

Chagas, Rio de Janeiro RJ, Brasil.

\section{Correspondence:}

Abelardo Q. C. Araújo; Instituto de Neurologia Deolindo Couto, UFRJ; Avenida Venceslau Braz, 95; 22290-140 Rio de Janeiro RJ, Brasil; E-mail:abelardo.araujo@gmail.com

Conflict of interest:

There is no conflict of interest to declare.

Received 27 April 2017

Accepted 04 May 2017
$\mathrm{W}$ hen Stanley Prusiner coined the term "prion" in 1982, which he defined as a small infectious pathogen containing protein but lacking nucleic acid, the scientific world watched amazed a revolution in the fields of biology and medicine. Prusiner deservedly won the 1997 Nobel Prize for his achievement succeeding Carleton Gajdusek who had won the same prize in 1976 for his discoveries in this field ${ }^{1}$.

Prion diseases are neurodegenerative conditions that have long incubation periods and progress inexorably once clinical symptoms appear. Five human prion diseases are currently recognized: Kuru - currently extinct, Creutzfeldt-Jakob disease (CJD), variant CreutzfeldtJakob disease (vCJD), Gerstmann-Sträussler-Scheinker syndrome (GSS), and fatal familial insomnia $(\mathrm{FFI})^{2}$.

GSS is an extremely rare disease with an incidence of 1 to 10 cases per 100 million persons/year. It is inherited in an autosomal dominant pattern with virtual complete penetrance. To date, less than30 separate kindreds have been identified throughout the world ${ }^{3}$.

The clinical hallmark of GSS is a progressive cerebellar ataxiaalong with dementia of different levelsin patients entering midlife, although the onset of symptoms in older patients has been reported. The course of the illness typically advances for approximately five years until death. Dysesthesia, hyporeflexia, and proximal weakness in the legs are also early signs. Contrary to what is found in CJD, myoclonus istypically absent in GSS. The presence and degree of dementia is also highly variable among affected families and within individuals from the same family. Part of the variability of expression of this illness has been attributed at least in part to differences in the underlying PRNP mutation or the associated polymorphisms in codon $129^{3}$.

The diagnosis of GSS is very difficult to be made based solely on clinical grounds. The cerebrospinal fluid (CSF) and the electroencephalogram (EEG) are unspecific. Magnetic resonance imaging (MRI) is neither specific nor sensitive but may show areas of decreased T2 signal in the striatum and midbrain in some patients. The best way to diagnose GSS in vivo is through the demonstration of PRNP gene mutations since the vast majority of cases are familial, and all patients with definite GSS have been found to have these mutations. The neuropathological analysis of brain tissue reveals the presence of kuru-like plaques in highest density in the cerebellum but also elsewhere in the brain. These plaques are often multicentric with radiating spicules and are accompanied by microglial changes; they stain for $\operatorname{PrP}^{\mathrm{Sc}}$ and are PAS positive ${ }^{2,3}$.

In the present issue of Arquivos de Neuropsiquiatria, Smid et al presents the most comprehensive clinical, genetic and neuropathological study on GSS ever made in Brazilian families. This important report emphasizes the need to maintain a high level of suspicion for the diagnosis of GSS in cases of slow-onset cerebellar ataxia, associated or not with dementia, particularly in those cases who run in families. At the same time, this study emphasizes the need to support a network of nationally coordinated researchers with different areas of expertise that can serve as reference to other physicians to contribute, each one in their own capacity, to the diagnosis of cases of rare neurological diseases ${ }^{4}$. 
1. Prusiner SB. Prions. Proc Natl Acad Sci USA. 1998:95(23):13363-83. https://doi.org/10.1073/pnas.95.23.13363

2. Araujo AQC. Prionic diseases. Arq

Neuropsiquiatr. 2013;71(9B):731-7. https://doi.org/10.1590/0004-282X201301461

3. Takada LT, Kim MO, Cleveland RW, Wong K, Forner SA, Gala II et al. Genetic prion disease: Experience of a rapidly progressive dementia center in the United States and a review of the literature. Am J Med Genet B Neuropsychiatr Genet. 2017;174(1):36-69. https://doi.org/10.1002/ajmg.b.32505.

4. Smid J, Studart Neto A, Langemberger MC, Machado CF, Nóbrega PR, Canedo NHS et al. High phenotypic variability in Gerstmann-Sträussler-Scheinker disease. Arq Neuropsiquiatr 2017;75(6):331-38. https://doi.org/10.1590/0004-282X20170049 